February - 2008

\title{
Book Review - De la educación a distancia a la educación virtual
}

\begin{abstract}
Authors: Lorenzo García Aretio, Marta Ruiz Corbella and Daniel Domínguez Figaredo. (2007). De la educación a distancia a la educación virtual. Barcelona: Editorial Ariel, S.A. ISBN: 978-84-344-2666-5
\end{abstract}

Reviewed by: Peter S. Cookson, Director Académico, El Consorcio Clavijero, Mexico

Editor's Note: This book is published in Spanish only.

This book comprises the reflections of knowledgeable and seasoned distance education practitioners on the paradigm shift from (fourth generation) distance education to (fifth generation) virtual education. The authors are seasoned and prominent academics at the Distance Education University (UNED) of Spain. Lorenzo García Aretio is the Unesco Distance Education Chair and Dean, Marta Ruiz Ruiz is a professor and Vice-Dean, and Daniel Domínguez Figaredo is a faculty member and researcher in the Department of Educational Theory and Social Education.

For the benefit of English language readers, in this review I will present an overview of some of the numerous insights presented by the authors.

The worldwide boom in the digital technologies has created the information society. As people seek to grapple with the tsunami of information sources, the technologies of information and communication have become readily available, rendering irrelevant location and timing of access to sources of knowledge. The information society sets the stage for the knowledge society that enables learners to employ the technologies to construct their own knowledge, making possible the learning society. The evolution in recent years of interactive and collaborative technologies makes possible student-centered learning with continuous interaction among the participants in the process. Time and space constraints disappear entirely, making way to a new concept of 'virtuality' that is revolutionizing all forms of education.

García, Ruiz and Dominguez explain that, given the advent of digital technologies, distance education has progressed through five generations of development. The first generation, until 1965, was marked by reliance on printed media distributed mainly through postal services. The second generation, from 1965 to 1985, was marked by the emergence of radio and television technologies. The third generation, from 1985 to 1995, was marked by the integration of computer-assisted instruction and inception of technologies of information and communication (TICs). The fourth generation, virtual education, from 1995 to the present, saw the convergence on the Web of all of the elements of the previous generations. The massive adoption of home- and business-based PCs and affordable and broadband connections to the Internet, learning management systems, computer conferencing, learning communities, the offer of Internet-based 
courses and degrees by both small and large universities worldwide and, even in the poor nonindustrialized countries the emergence of publicly funded 'telecenters' and cybercafés, are all innovations that have characterized this fourth generation that continues to this day. To the fourth generation the authors of this book point to a fifth generation that they call 'e-learning.' In addition to many of the features of previous generations, this fifth generation is centered on constructivist approaches to learning. Students cease to be receptors of the learning selected and delivered by their instructors. Instead, capitalizing on the use of technologies based on the Internet, they share with their teachers responsibility for selecting the what and the how of their own learning. In light of the requirements of this fifth generation of distance education and the need for students to be engaged in a constant process of learning and unlearning throughout life, García, Ruiz and Domínguez contend that training for self-learning must be a priority in every teaching-learning process.

Besides enabling attainment of specific learning objectives, the focus of all education programs is development of learners to participate actively in the economic, social, and cultural life as well as to adapt to changing conditions in the context of the knowledge society in which they live. Given such developments as network bandwidth and speed, fiber optics, wireless connections, mobile Internet, reduced connection costs, improved navigation tools in virtual learning, and collaborative technologies, distance and virtual forms of education now provide enriched teaching learning contexts, ideally suited to enable effective lifelong education. Distance education is no longer regarded solely as a way for individuals to compensate for lost opportunities to participate in classroom-based learning. Because conventional face-to-face education cannot meet the demands of lifelong education in contemporary society, distance education is increasingly perceived as a viable educational alternative for the majority of the population. The worldwide resurgence of interest and involvement in distance education, at least in industrialized countries, is making the opportunity of access to lifelong education a reality for all segments of the population. As more and more face-to-face educational institutions progressively offer more distance programs, the boundaries between face-to-face and distance instruction are dissolving.

According to García, Ruiz and Domínguez, teaching in virtual education involves,

... the processes of orientation that respond to the tasks of attending individually to each student, guiding and mediating their learning, helping them to promote their interests, tackling positively different difficulties that occur throughout their learning. Nobody questions the necessity of the task of guiding and orientation, both group and personal, of motivation, individualized help in the whole process of learning, being, if it fits, more necessary in distance education for effective learning in flexible environments in which to promote self-directed learning. The ICTs provide, in this sense, great possibilities of interaction between the learners and the educator, and a continuous and dynamic interrelationship among all of them, outside of all of the spatiotemporal coordinates. (p. 180)

The authors advance the view that despite the advancement of the TICs, the educator remains the fundamental agent in interaction with the learner who remains the chief protagonist. Without the interaction between these two and the guidance, help, and mediation of the educator, education would not be possible. While pre-Internet forms of distance education have been criticized for the lack of two-way interaction between these two, this is no longer true.

Although teachers in virtual education continue to transmit information, they also plan and manage the information in such a way that students, more than mere passive readers of pages, may construct their own information structures and then convert them to knowledge. This implies 
a new relationship between new learning practices and knowledge, underscoring the importance of creating flexible learning environments. Any process of education is clearly insufficient if based exclusively on the knowledge of a teacher or a specific study manual. In virtual education, learners, by employing a diversity of technologies and channels of communication, are active users of flexible and self-directed learning.

With added interactivity, hyper-textuality, and multimedia in virtual education environments, teachers no longer serve as mere transmitters of information. Their teaching functions and roles have become more complex and subdivided among a team of professionals who input knowledge, communications, and technologies to facilitate flexible learning. These professionals assume different roles: planners, course designers, materials and media, content experts, educational technologists, specialists, and technicians who produce didactic materials; supervise, plan, and coordinate diverse activities; consult, counsel, advise students, and evaluate various program aspects.

Lending credence and coherence to all of these functions, the teacher continues to be responsible as initiator of mediated learning in virtual environments. To ensure quality education, besides indepth knowledge of their own discipline, virtual educators must also possess the following attributes:

- Greater knowledge of teaching, psychology, sociology, and technology

- Knowledge of distance education

- $\quad$ Competencies, skills, abilities, attitudes, values, and knowledge of how to learn and to access and discriminate among information sources

- $\quad$ Ability to empower others to exercise control over their own learning

- Knowledge of how to respond to such aspects of social change as plurality, globalization, interdependence among groups, conflict resolution

- $\quad$ Mastery of technological culture

Previous generations of distance education did not require the direct involvement of teams of education specialists. Although first generation distance education involved specialists, these were not directly involved in pedagogical development. In second generation distance education, from 1960 to 1985, radio and television technicians merely carried out the decisions of pedagogues. In third generation distance education, from 1985 to 1995, involving applications of TICs, teachers could not do everything and thus worked as a team with other specialists. In fourth generation digital distance education, the technology revolution took off and brought with it the advent of collaborative technologies, learning centered on students, interaction among actors, disappearance of spatiotemporal limitations and 'virtuality' revolutionizing all education. This radical transformation of education practice makes possible and necessary student self-directed learning, as well as collaboration and cooperation among teachers and students.

Numerous technological developments have also accompanied the rise of the Internet. Mobile phones are becoming a vehicle for education for people constantly on the move. Standards are being developed for design of learning materials and tools. Technologies for voice recognition and conversion of text to voice offer possibilities for improved vertical and horizontal interaction, simulation, and models and tools for visualization. Virtual learning guides are being developed. Study programs are increasingly aimed at citizens of different countries. Communication technologies offer learning possibilities for students with physical handicaps, development of virtual learning guides, and a plethora of international study programs for people in different countries. 
While both pre- and post-Internet forms of distance education create learning opportunities characterized by flexibility, accessibility, socialization, interactivity, individualization, and motivation, distance education with ICT adds such features as interactivity, collaboration, macro information, recuperation of intelligence, greater ease of interactivity, greater access, diversity of approaches, immediacy, access to information independent of spatial and temporal considerations, multiple formats, multi-directionality, tele-ubiquity, freedom to generate and disseminate ideas, and inter-disciplinarity.

These post-Internet innovations have contributed to the emergence of different models of distance education. Institutional models include uni-modal institutions and dual- or bi-modal institutions. Organizational models reflect synchronous or asynchronous or both patterns of relations between teachers and students. Pedagogical models encompass traditionally conservative and authoritarian, participative, behaviorist, and constructivist pedagogical orientations. Other models center their focus on such aspects of the learning-teaching process as the teacher, the student, technology, interaction, or comprise integrative models. Courses differ in how they relate to content: content with support, wrap around, and integrative courses that provide flexible content with support and collaboration. Some courses are conducted exclusively at a distance; while other mixed courses are conducted primarily via distance instruction combined with some face-to-face instruction.

Ruiz and Domínguez describe six types of distance education that correspond to six technological models of utilization of the media. (1) The classical or correspondence study model consists of print-based study materials. (2) The multimedia model draws on multiple media such as radio and television. (3) The computer supported model combines multimedia and consists of computerassisted instruction and computer-managed instruction. (4) The Internet-based model includes computer mediated communication and computer-based multimedia, combined with a Web-based learning management system; the result is referred to as e-learning. (5) Mobile or m-learning refers to mobile learning from the Internet via cellular phones and wireless networks, "maximizing portability, interactivity and connectivity" (p. 82), particularly for people on the move. (6) Blended learning, or semi face-to-face learning, sometimes referred to as hybrid learning, combines face-to-face and distance learning.

Digital teaching-learning systems adapted to the needs of students have progressed through three stages of development: (1) virtual campuses established by educational institutions; (2) digital platforms that permit adaptation of technological tools and creation of closed spaces for the development of specific educational programs; and (3) cyberspace characterized by a constructivist model of learning that calls for students to practice and communicate among themselves and their teachers within the open spaces of the Web.

The educational strategies employed for the first two stages imitate those that occur in formal face-to-face classroom settings in which professors teach groups of students. These include word processing, virtual forms and synchronous chat in order to provide a learning environment analogous to a face-to-face class. In contrast to the closed spaces of the first two stages of distance education, the third stage builds on a set of applications under the name of Web 2.0 that corresponds to a unique philosophy that permits users to take charge of what happens on the Internet. They are empowered to access and produce diverse content without the intervention of others. Because it is no longer necessary to know programming languages to disseminate and access information on the Internet, anyone can interact with the help of applications, many of which are freely available. All of these developments open the door to the democratization of the network, to its opening up to society, and to a reduction of the digital gap whereby only advanced 
users could enjoy the most interactive applications (pp. 99-100). What Ruiz and Domínguez refer to as E-learning 2.0,

. . . centers its interest in the learning community and in the capacity of learners to produce knowledge that results from their social participation in a rich and stimulating setting, with a high amount of interactivity and freedom to receive and produce educational content. (p. 100)

A key theme repeated throughout the book is that in Web 2.0, users are more than passive readers of pages. For that reason teachers must plan and manage the instructional process in such a way that students construct their own knowledge and thus play a significant role in determining the processes that occur in the spaces that they 'inhabit.' The authors even recommend that in creating course content, teachers leave some content incomplete so that students themselves may identify additional resources. Following this recommendation would mean that students can gain competence in searching, analyzing, interpreting, and selecting information that becomes the teaching-learning content.

To understand how social relations influence both individual and group behaviors in learning communities, it is important to understand the social dynamics of cyberspace. In their discussion of learning communities in virtual settings, the authors address such topics as interaction and communication via the Internet, morphology of virtual relationships, identity and communication on the Internet, social participation in cyberspace, Internet culture, learning communities in cyberspace, the value of the community, socio-educative practice contexts, and facilitating knowledge.

Focusing on how the Internet combines the distribution of information with social interaction, the authors explain,

Cyberspace specifically provides social relations produced in a virtual, rather than a Euclidean setting. The unique characteristics of extraterritoriality and disembodiment of cyberspace gives place to human sociability that does not require physical contact or corporal presence in order to establish stable contacts and linkage. Consolidation of these relational linkages in cyberspace permits the formation of personal learning communities that enable their members to access, share, co-generate and co-construct knowledge that stems from their interrelationships and communication interchanges.” (p. 129)

The new educational scenarios not only involve technological support for innovation, but also transform the ways to create, accumulate, store, and transfer information. When planning distance education activities, it is essential first to determine what educational objectives are sought and what content is intended to be learned (p. 144). Educational objectives are relevant as points of reference for all members of the multidisciplinary teams responsible for educational interventions and for the students.

Educational objectives are relevant for all members of the multidisciplinary teams who intervene for students in distance education activities. They provide coordinates for making decisions in the planning and implementation of every distance education action. For students, they serve a double purpose. First, they enable determination of the previous knowledge necessary to gain the final objectives, in terms of content, competencies, abilities and skills, attitudes and values, and equally in terms of the end of activity, they permit evaluation of the learning results acquired (p. 145). Second, they provide students with the information necessary about what is intended, thus contributing to their motivation. 
Within a constructive perspective of e-learning, learning objects, digital learning resources have also gained importance in recent years. With digitization, creation of repositories, learning management systems, learning objects have become an important component of e-learning. Ruiz and Domínguez point out how such digital learning resources that are reused in multiple educational settings can be guided by such psychological orientations as behaviorism, cognitivism, and constructivism. One view of teaching is as an industrial process, centered in the minimization of expenses (materials, staff, return or unit cost). Another view is as an open and flexible process, centered on the subject and processes of learning.

The authors point out that the ideal outcome of all education is to enable learners to learn how to learn, learn to be, learn to do, and/ or learn to live together with others. In reaching these outcomes, objectives provide coordinates for making decisions regarding the planning and implementation of the set of learning of activities that comprise the online course, objectives enable identification of competencies, skills, attitudes, and values that learners should possess when beginning a distance education course, as well as those that they should achieve at the end of the course; they are thus instrumental to the formation of motivation. They also orient members of the multidisciplinary teams responsible for creating the courses.

Analyzing the role of professors and trainers in digital teaching and learning systems, García, Ruiz and Dominguez explain that, despite the advancement of the TICs, the educator remains the fundamental agent in the interaction with the learner who remains the chief protagonist. Without that interaction between these two and the guidance, help, and mediation of the educator, education would not be possible. While pre-Internet forms of distance education have been criticized for the lack of two-way interaction, this is no longer true. Given the plethora of information sources now available on the Internet, the educator is no longer the principal transmitter of knowledge.

According to the authors,

Training for self-education should be the priority objective for every teaching-learning process. In order to acquire the specific competencies, knowledge and attitudes for whenever and wherever needed, students should be engaged in a lifelong process of learning and unlearning that is necessary to face the continuous changes of reality in which they are inserted. Thus the necessity of mastery of strategies for search, assessment, selection, processing, integration and evaluation of existing information on the networks, more than of strategies of copying texts and summaries that are developed and transmitted as fundamental elements of learning. (p. 145)

The ICTs create opportunities for continuous dynamic interrelationships among learners and educators. With regard to the qualifications of instructors in digital environments, García, Ruiz and Domínguez include the following considerations:

- Knowledge of one's discipline as well as of teaching, psychology, sociology, and technology for quality of education

- Because of their complexity, it is not possible to master occupational roles with initial education alone; initial and continuous education is essential 
- Within the context of an ever changing society, learning must be focused on competencies, skills, abilities, attitudes, and values rather than on knowledge alone. There is no longer only one place for learning

- Competence in the use of TICs essential to continuous dynamic interrelationships among learners and educators

- The pedagogical aspects of planning, managing, and teaching via distance and virtual education

The authors point to the conditions (i.e., the "global variables") that signal the radical transformation of educational practice from previous forms of distance education to virtual education:

- Transformation of teaching as a profession that now requires knowledge of such areas as one’s discipline, teaching, psychology, sociology, and technology.

- It is no longer possible to master the complexity of occupation and professional tasks with mere initial education. It is now possible to pursue both initial education and continuous education via virtual education environments.

- The need for continuous preparation for an ever changing society, focusing on competencies, skills, abilities, attitudes, and values, rather than on knowledge alone. There is no longer only one place for learning, as informational sources have multiplied, and educational scenes and agents have diversified and multiplied, and individuals are now endowed with control over their own learning.

- Social change attendant to twenty-first century society is marked by pluralism, globalization, and interdependence among groups, along with multiculturalism and a consequent need for personal development within an ever more multicultural context.

- Current society is influenced by digital conditions of technological culture from which education cannot be aloof.

García, Ruiz and Dominguez assert that in the digital era every professional needs to have a basic mastery of these global variables.

To solve problems and situations in real contexts, distance educators need to have highly developed competencies of reading comprehension, writing ability, mastery of digital and iconic reading, use of software, and mastery of communication channels. In addition, they need to have the ability to participate on interdisciplinary teams and traits of initiative, responsible work, flexibility, the capability to unlearn and learn, as well as to stay up-to-date with the evolution of TICs.

Such a plan permits the design of specific instructional projects that, in turn, comprise specific educational programs.

Garcia, Ruiz and Dominguez approach the topic of instructional design within the context of educational planning. They conceptualize planning as a shared and systematic vision that anticipates the future. Planning, as an overall rational strategy, permits the formation of an 
education action plan. To guide the development of a specific plan, the authors introduce key questions: questions concerning the nature of the project are what, why, and for what; questions regarding temporal and spatial location are where and when; questions regarding the actors involved are to whom and who; questions regarding organization and programming are how much, how, and with what. Once a plan of action for a three-year period is in place, specific projects, and programs within projects, can then be designed.

Consonant with the institutional context in terms of needs, possibilities, and ideas, such a plan enables avoidance of both routine and improvisation. Paralleling the phases of the ADDIE (i.e., analysis, design, development, implementation, and evaluation) model of instructional design, the process they describe calls for identification of specific objectives and educational priorities, and procedures for actions.

Their descriptions of each of the planning and design steps provide useful guidance to both novice and experienced content experts and instructional designers. They offer valuable guidance for grounding education plans, offering useful points of reference for designing educational programs.

The authors do not distinguish between education that enables people to resolve specific problems and education that is designed to enable learners to attain mastery of specific subjects. The planning process they propose, however, can apply to the creation of virtual higher education courses if those who are responsible for 'writing' the courses assume a problem-based or competency-based approach to their course design.

The final chapter of this 'treasure trove' is a valuable guide to the world of virtual education. It is full of information and insights about how to determine whether one's virtual education program meets standards of excellence. After defining quality in terms of the dimensions of functionality, effectiveness, efficiency, availability, information, and innovation, they turn their attention to the quality of instructional materials. Anyone interested in measurement and appraisal of the quality of particular virtual education programs will find it useful to apply this quality assurance scheme based on these six dimensions of context, goals, inputs, processes, results, and improvements.

García, Ruiz and Domínguez report that the emphasis on quantitative standards in the 1960s and 1970s gave way to the tendency to examine the coherence among different educational objectives in the 1970s and 1980s; that, in turn, gave way in the 1990s to systems of values and social expectations. That emphasis has now been superseded by criteria, standards, indicators, evaluation, accreditation, etc., as evidenced by the European Foundation for Quality Management (EFQM) and the National Distance Education University (UNED) of Spain, which promote quality assurance in higher education in general, and in higher distance education in particular. The authors report parallel efforts by such organizations as the US-based Institute for Higher Education Policy and the Virtual Center for the Development of Quality Standards for Higher Distance Education in Latin America and the Caribbean.

The numerous lists of components, qualities, or criteria of different aspects of the distance education enterprise are some of the most useful features of this book. Such lists can provide added value to such professional development activities as assigned readings, checklists for weighing the relative strengths of our own distance learning programs, prompts for online discussions with students of the discipline of distance education, or as training materials for educators who need to acquire competence in creating or teaching courses in virtual education settings. The authors provide abundant criteria for evaluating the quality of materials as well as the performance of different specialists of multidisciplinary teams. 
In their review of the multiple aspects of distance and virtual education, the authors discuss in detail valuable insights based on distance education theory, research, and practice. Such insights to be gleaned from this work can be especially valuable for those who are responsible for the training and/ or education of others to participate in these tasks. As the academic director of a higher distance education consortium in a developing country, many of the authors' points enrich the training for both subject matter experts who create as well as the academics who teach our online courses.

For its comprehensive and encyclopedic scope as well as its detailed analytical review of the distance education literature published in both English and Spanish, I highly recommend this book as a source of meaningful and useful concepts and ideas for anyone seeking to increase their competence as a practitioner of distance and virtual education. If this book were available in English, I would regard it as a 'must have' for the professional library of every distance educator, as well as 'required reading' for anyone completing graduate studies related to distance education and/ or educational technology. It would be particularly helpful to those who are responsible for the training and education of teachers to design, develop, and/ or implement any form of virtual education. In my own case, many of the principles and practices that the authors review reinforce the professional development that my organization conducts for both subject matter experts who create and professors who teach online courses. It is a rich source of concepts and ideas for anyone seeking to become a more knowledgeable and competent practitioner of distance and virtual education.

Even for native readers of Spanish, the reflections that comprise this book are deep. They do not make for a quick read. They merit profound interactive dialogue in order to capitalize fully on the implications for one's own distance/ virtual education practice. With their encyclopedic perspective and drawing on the sources available in both English and Spanish, Garcia, Ruiz and Dominguez' analysis of familiar elements of distance and virtual education experience provides insights that support conscientious and knowledgeable distance education practice. At least for Spanish language readers, this book constitutes a significant contribution to the field of distance education. Unfortunately, I know of no similar book that has been written for English language readers. 